\title{
One of the criteria for selecting a contractor for high-rise construction
}

\author{
Zalina Tuskaeva ${ }^{1, *}$ and Timur Tagirov ${ }^{2}$ \\ ${ }^{1}$ FSBO HE North-Caucasian Institute of Mining and Metallurgy (State Technological University) 44 \\ Nikolaeva Str., Vladikavkaz, 362021, Russia \\ 2 Moscow State University of Civil Engineering, Yaroslavskoe shosse, 26, Moscow, 129337, Russia
}

\begin{abstract}
The mechanisms for management of the building complex used and proposed to date do not always provide the required result in the assessment of the construction organization facilities. Therefore, the development of new effective methods for such an assessment is an urgent task especially in questions related to high-rise construction. The article formally sets the task of assessing the technical facilities of a construction organization. Due to the use of expert methods, the weighted values of the coefficients of local indicators for technical facilities are identified.
\end{abstract}

\section{Introduction}

High-rise buildings are an integral part of modern city-planning policy of megacities. They reflect financial possibilities of a state, a particular region or city, $t$ construction technology and technical equipment level, availability of the required specialists in design and construction [1-5].

According to the data of the Council on Tall Buildings and Urban Habitat 101 high-rise buildings had been built in the RF by 2014 [6].

During the hundred years of high-rise buildings design and construction, the world practice has accumulated relevant theoretical and practical experience, identified the key problems of their design, constru.ction and maintenance. The development of high-rise construction in the RF identified a number of serious problems to be solved, and namely:

- Disadvantages in legal framework;

- lack of necessary experience in design and construction;

- lack of relevant personnel;

- inadequate equipment of contractors [4].

Although nowadays the required minimum legal and regulatory framework for choosing a contractor has been created, many issues remain insufficiently developed. Applicants are often selected with no scientific and methodological regard of their technical and financial status and ability to manage the project. A proper systematic evaluation is not carried out, resulting in errors in the selection of the contractor and failure of contractual obligations.

The intensification of problems associated with high-rise construction requires an assessment of contractors' reliability in terms of technical compliance or equipment.

${ }^{*}$ Corresponding author: tuskaevazalina@yandex.ru 
To solve this problem, it is necessary to develop a methodology for assessing technical facilities of organizations committed to win the contract for high-rise construction. This will limit access of uncompetitive, technically inadequately equipped contractors to high-rise construction.

Construction machinery is one of the most important criteria for assessing the level of the construction organization technical equipment, since modern construction industry uses a large variety and number of labor saving devices [7-18].

Increase in the machinery and its maintenance cost raise the questions of optimization of technical and economic performance indicators, which ensure an increase in productivity and a reduction in the cost of construction. The management mechanisms used and proposed today do not provide the desired result in the assessment of the level of construction works mechanization [17]. Therefore, the development of methods for assessing the overall technical facilities of a construction organization claiming to win a contract for a high-rise building is one of the key tasks to solve the problems associated with the construction of skyscrapers.

\section{Methodology}

Many modern methods of assessing the activities of organizations are based mainly on parametric one-criterion estimates. Such an approach does not allow fully reflecting the peculiarities of the problem in question and taking into account the mutual influence of a set of indicators [19].

In general, the task of assessing the technical facilities of a construction organization can be represented as follows:

$$
\mathrm{y}_{t p}=\sum_{i=1}^{k}\left(d_{i} \cdot X_{i}\right) / \sum_{i=1}^{k} d_{i}
$$

Where $d_{i}$ - weighted coefficient of $i$-factor of technical facilities;

$\mathrm{k}-$ number of factors examined;

$X_{i}$ - discreet values of $i$-factor.

This problem is divided into two components:

1. Quantitative estimation of weight coefficients of technical facilities factors;

2. Development of a technique for calculating the discrete values of each factor.

This article is devoted to the solution of the first part of the problem-the determination of the quantitative values of $d_{i}$.

The procedure for assessing technical facilities is necessary to analyze the capacities of the construction organization in high-rise building construction included into the category of unique buildings and structures. To develop this idea, we will immediately formulate the problems: "How to assess these capacities?", "Which of the performance indicators of the contractor organization are the most significant and important?", "How to assess comprehensively?". The entire list of issues under consideration requires a detailed account of the actual capabilities of the contractor.

The possibilities of applied mathematics for finding effective solutions are limited. To solve such problems, heuristic methods are widely used, based on the simulation of the decision-making process by a person who has the necessary information and possesses sufficient experience. The solutions chosen in this case are the best ones that can be obtained with the help of the developed algorithm.

A combination of heuristic methods for the random search of successive approximations with quantitative methods for solving optimization problems is

Indicators reflecting certain areas of the state of contractor technical facilities are presented in the work by particular quantitative indicators. To summarize the assessment, it 
is advisable to use a composite set of indicators, called the integral indicator of the technical potential level.

The study and choice of indicators will be performed consistently in several stages:

1. Drawing up a list of indicators that objectively reflect the entire level of technical equipment.

2. Creating a group of experts necessary to identify the most significant indicators.

3. Conducting an expert survey and processing the results in order to identify significant indicators.

\section{Results}

The process of forming or selecting the most significant indicators was carried out by the expert evaluation method, since it is impossible to assign quantitative values to a number of factors included into the investigated problem, using other methods [19]. The required number of experts was defined according to the simplified Wentzel formula [20]:

$$
N=k \cdot P_{\mathrm{d}} /\left(P_{\mathrm{oshc}}+0,5\right)=11 \cdot 0.95 /(0.05+0.5)=19
$$

A group of 22experts were offered the following indicators for assessing the level of technical facilities (see table 1).

Table 1. Indicators of technical facilities

\begin{tabular}{|c|c|c|}
\hline $\begin{array}{c}\text { Item } \\
\mathrm{N}\end{array}$ & Indicators & Symbol \\
\hline & $\begin{array}{l}\text { Indicators characterizing the material component of technical facilities } \\
\text { I. Indicators characterizing the material component of technical facilities (availability } \\
\text { ) }\end{array}$ & \\
\hline 1 & Level of basic machines facilities & $\mathrm{X} 1$ \\
\hline 2 & Level of completeness of construction equipment & $\mathrm{X} 2$ \\
\hline 3 & Proportion of machines exceeding service life & $\mathrm{X} 3$ \\
\hline \multirow[t]{2}{*}{4} & Proportion of equipment produced overseas & $\mathrm{X} 4$ \\
\hline & $\begin{array}{l}\text { II. Indicators characterizing the material component of technical facilities } \\
\text { (management) }\end{array}$ & \\
\hline 5 & Basic machines availability coefficient & $\mathrm{X} 5$ \\
\hline 6 & Coefficient of the intensity of construction machinery use & X6 \\
\hline \multirow[t]{2}{*}{7} & $\begin{array}{l}\text { The level of compliance with environmental requirements for construction } \\
\text { equipment }\end{array}$ & $\mathrm{X} 7$ \\
\hline & $\begin{array}{l}\text { III. Indicators characterizing the material component of technical facilities } \\
\text { (economic characteristics) }\end{array}$ & \\
\hline \multirow[t]{2}{*}{8} & The percentage (level) of use of depreciation charges by the organization & $\mathrm{X} 8$ \\
\hline & IV. Indicators characterizing the labor component of technical facilities & \\
\hline 9 & Coefficient of operators sufficiency & $\mathrm{X} 9$ \\
\hline 10 & Coefficient of operators qualifications & $\mathrm{X} 10$ \\
\hline 11 & Level of use of progressive forms of payment & $\mathrm{X} 11$ \\
\hline
\end{tabular}

The results of expert assessment of technical facilities indicators are presented in table 2 . 
Table 2. Results of expert assessment

\begin{tabular}{|c|c|c|c|c|c|c|c|c|c|c|c|}
\hline \multirow{2}{*}{ Indicators } & \multicolumn{10}{|c|}{ expert mark } \\
\cline { 2 - 13 } & 1 & 2 & 3 & 4 & 5 & 6 & 7 & 8 & 9 & 10 & 11 \\
\hline $\mathrm{X} 1$ & 10 & 10 & 9 & 10 & 8 & 9 & 9 & 10 & 8 & 10 & 9 \\
\hline $\mathrm{X} 2$ & 8 & 6 & 8 & 7 & 8 & 7 & 9 & 10 & 8 & 9 & 7 \\
\hline $\mathrm{X} 3$ & 5 & 7 & 7 & 8 & 7 & 7 & 6 & 5 & 6 & 6 & 6 \\
\hline $\mathrm{X} 4$ & 8 & 9 & 7 & 9 & 10 & 8 & 6 & 10 & 6 & 9 & 10 \\
\hline $\mathrm{X} 5$ & 9 & 10 & 9 & 10 & 10 & 10 & 10 & 10 & 9 & 9 & 10 \\
\hline $\mathrm{X} 6$ & 10 & 9 & 10 & 10 & 10 & 10 & 10 & 10 & 10 & 9 & 8 \\
\hline $\mathrm{X} 7$ & 6 & 5 & 5 & 6 & 7 & 7 & 6 & 5 & 4 & 8 & 5 \\
\hline $\mathrm{X} 8$ & 8 & 7 & 9 & 9 & 6 & 6 & 4 & 7 & 6 & 6 & 7 \\
\hline $\mathrm{X} 9$ & 7 & 10 & 9 & 7 & 10 & 9 & 9 & 10 & 10 & 9 & 10 \\
\hline $\mathrm{X} 10$ & 10 & 10 & 9 & 8 & 10 & 9 & 9 & 10 & 9 & 10 & 8 \\
\hline $\mathrm{X} 11$ & 9 & 7 & 9 & 8 & 10 & 10 & 7 & 10 & 9 & 8 & 9 \\
\hline
\end{tabular}

Table 2. Results of expert assessment. Continued

\begin{tabular}{|c|c|c|c|c|c|c|c|c|c|c|c|c|c|}
\hline \multirow{2}{*}{ Indicators } & \multicolumn{10}{|c|}{ expert mark } & $\begin{array}{c}\text { Average } \\
\text { mark }\end{array}$ & $\begin{array}{c}\text { Varation } \\
\text { coefficient }\end{array}$ \\
\cline { 2 - 17 } & 12 & 13 & 14 & 15 & 16 & 17 & 18 & 19 & 20 & 21 & 22 & 23 & 24 \\
\hline $\mathrm{X} 1$ & 8 & 9 & 9 & 8 & 10 & 9 & 10 & 9 & 10 & 8 & 9 & 9,14 & 0,084 \\
\hline $\mathrm{X} 2$ & 9 & 6 & 7 & 6 & 7 & 6 & 10 & 9 & 7 & 7 & 7 & 7,64 & 0,168 \\
\hline $\mathrm{X} 3$ & 9 & 9 & 7 & 6 & 7 & 6 & 6 & 8 & 8 & 7 & 7 & 6,82 & 0,153 \\
\hline $\mathrm{X} 4$ & 6 & 6 & 8 & 5 & 8 & 9 & 6 & 6 & 8 & 6 & 8 & 7,64 & 0,209 \\
\hline $\mathrm{X} 5$ & 9 & 9 & 9 & 9 & 10 & 9 & 10 & 9 & 8 & 8 & 9 & 9,32 & 0,071 \\
\hline $\mathrm{X} 6$ & 10 & 10 & 9 & 10 & 10 & 10 & 10 & 10 & 9 & 10 & 10 & 9,73 & 0,058 \\
\hline $\mathrm{X} 7$ & 6 & 5 & 6 & 4 & 7 & 4 & 7 & 7 & 3 & 4 & 3 & 5,45 & 0,263 \\
\hline $\mathrm{X} 8$ & 7 & 5 & 5 & 5 & 6 & 6 & 7 & 5 & 4 & 3 & 6 & 6,09 & 0,244 \\
\hline $\mathrm{X} 9$ & 10 & 10 & 9 & 10 & 10 & 9 & 10 & 9 & 10 & 10 & 9 & 9,36 & 0,080 \\
\hline $\mathrm{X} 10$ & 9 & 10 & 10 & 8 & 9 & 10 & 9 & 10 & 8 & 10 & 9 & 9,27 & 0,083 \\
\hline $\mathrm{X} 11$ & 9 & 7 & 9 & 6 & 9 & 10 & 10 & 7 & 7 & 6 & 8 & 8,36 & 0,162 \\
\hline
\end{tabular}

The average mark is defined as the quotient of dividing the sum of the proposal marks by the number of experts. To establish the degree of reliability of the study conducted, the average proposal mark, variance and standard deviation were determined.

The average mark for indicator $i$ is defined according to the formula:

$$
\overline{\mathrm{C}_{\imath \jmath}}=\frac{1}{n} \sum_{j=1}^{m} C_{i j},
$$

Where $n$ - is the number of experts;

$$
m \text { - number of evaluation indicators; }
$$

$C_{i j}-$ evaluation of indicator $i$ by expert $j$;

$\overline{\mathrm{C}_{\boldsymbol{\imath}}}$ - average mark for indicator $i$.

The variance of marks is determined by formula:

$$
D_{i}=\frac{1}{n-1} \sum_{j=1}^{m}\left(C_{i j}-\overline{C_{l \jmath}}\right),
$$

where $D_{i}$ - variance of marks.

Variation coefficient is calculated by formula:

$$
\vartheta_{i}=\frac{\sqrt{D_{i}}}{\overline{C_{l \jmath}}}=\frac{\partial_{i}}{\overline{C_{l \jmath}}},
$$


Wher $\boldsymbol{\vartheta}_{\boldsymbol{i}}-$ variation coefficient;

$\boldsymbol{\partial}_{\boldsymbol{i}}-$ standard deviation.

Since the variation coefficient in all cases was within $0<\boldsymbol{\vartheta}_{\boldsymbol{i}}<0,3,-$ the consistency of experts is considered sufficient.

For the convenience of the comparative analysis, the marks are converted to ranks. Activities that score the minimum amount of ranks are considered to be the priority (table 3 )

Table 3. Results of expert evaluation ranking

\begin{tabular}{|c|c|c|c|c|c|c|c|c|c|c|c|}
\hline \multirow{2}{*}{ Indicators } & \multicolumn{10}{|c|}{ Expert mark } \\
\cline { 2 - 13 } & 1 & 2 & 3 & 4 & 5 & 6 & 7 & 8 & 9 & 10 & 11 \\
\hline $\mathrm{X} 1$ & 2,0 & 2,5 & 4,5 & 2,0 & 7,5 & 5,0 & 4,5 & 4,5 & 6,5 & 1,5 & 4,5 \\
\hline $\mathrm{X} 2$ & 7,0 & 10,0 & 8,0 & 9,5 & 7,5 & 9,0 & 4,5 & 4,5 & 6,5 & 5,0 & 8,5 \\
\hline $\mathrm{X} 3$ & 11,0 & 8,0 & 9,5 & 7,0 & 9,5 & 9,0 & 9,0 & 4,5 & 9,0 & 10,5 & 10,0 \\
\hline $\mathrm{X} 4$ & 7,0 & 5,5 & 9,5 & 4,5 & 3,5 & 7,0 & 9,0 & 10,5 & 9,0 & 5,0 & 2,0 \\
\hline $\mathrm{X} 5$ & 4,5 & 2,5 & 4,5 & 2,0 & 3,5 & 2,0 & 1,5 & 4,5 & 4,0 & 5,0 & 2,0 \\
\hline $\mathrm{X} 6$ & 2,0 & 5,5 & 1,0 & 2,0 & 3,5 & 2,0 & 1,5 & 4,5 & 1,5 & 5,0 & 6,5 \\
\hline $\mathrm{X} 7$ & 10,0 & 11,0 & 11,0 & 11,0 & 9,5 & 9,0 & 9,0 & 10,5 & 11,0 & 8,5 & 11,0 \\
\hline $\mathrm{X} 8$ & 7,0 & 8,0 & 4,5 & 4,5 & 11,0 & 11,0 & 11,0 & 9,0 & 9,0 & 10,5 & 8,5 \\
\hline $\mathrm{X} 9$ & 9,0 & 2,5 & 4,5 & 9,5 & 3,5 & 5,0 & 4,5 & 4,5 & 1,5 & 5,0 & 2,0 \\
\hline $\mathrm{X} 10$ & 2,0 & 2,5 & 4,5 & 7,0 & 3,5 & 5,0 & 4,5 & 4,5 & 4,0 & 1,5 & 6,5 \\
\hline $\mathrm{X} 11$ & 4,5 & 8,0 & 4,5 & 7,0 & 3,5 & 2,0 & 7,0 & 4,5 & 4,0 & 8,5 & 4,5 \\
\hline
\end{tabular}

Table 3. Results of expert evaluation ranking. Continued

\begin{tabular}{|c|c|c|c|c|c|c|c|c|c|c|c|c|}
\hline \multirow{2}{*}{ Indicators } & \multicolumn{10}{|c|}{ Expert mark } & $\begin{array}{c}\text { Average } \\
\text { rank }\end{array}$ \\
\cline { 2 - 14 } & 12 & 13 & 14 & 15 & 16 & 17 & 18 & 19 & 20 & 21 & 22 & 23 \\
\hline $\mathrm{X} 1$ & 8,0 & 5,0 & 4,0 & 4,5 & 2,5 & 5,5 & 3,5 & 4,5 & 1,5 & 4,5 & 3,5 & 4 \\
\hline $\mathrm{X} 2$ & 5,0 & 8,5 & 8,5 & 7,0 & 9,0 & 9,0 & 3,5 & 4,5 & 8,5 & 6,5 & 8,5 & 7 \\
\hline $\mathrm{X} 3$ & 5,0 & 5,0 & 8,5 & 7,0 & 9,0 & 9,0 & 10,5 & 7,0 & 5,5 & 6,5 & 8,5 & 8 \\
\hline $\mathrm{X} 4$ & 10,5 & 8,5 & 7,0 & 9,5 & 7,0 & 5,5 & 10,5 & 10,0 & 5,5 & 8,5 & 6,5 & 7 \\
\hline $\mathrm{X} 5$ & 5,0 & 5,0 & 4,0 & 3,0 & 2,5 & 5,5 & 3,5 & 4,5 & 5,5 & 4,5 & 3,5 & 4 \\
\hline $\mathrm{X} 6$ & 1,5 & 2,0 & 4,0 & 1,5 & 2,5 & 2,0 & 3,5 & 1,5 & 3,0 & 2,0 & 1,0 & 3 \\
\hline $\mathrm{X} 7$ & 10,5 & 10,5 & 10,0 & 11,0 & 9,0 & 11,0 & 8,5 & 8,5 & 11,0 & 10,0 & 11,0 & 10 \\
\hline $\mathrm{X} 8$ & 9,0 & 10,5 & 11,0 & 9,5 & 11,0 & 9,0 & 8,5 & 11,0 & 10,0 & 11,0 & 10,0 & 9 \\
\hline $\mathrm{X} 9$ & 1,5 & 2,0 & 4,0 & 1,5 & 2,5 & 5,5 & 7,0 & 4,5 & 1,5 & 2,0 & 3,5 & 4 \\
\hline $\mathrm{X} 10$ & 5,0 & 2,0 & 1,0 & 4,5 & 5,5 & 2,0 & 3,5 & 1,5 & 5,5 & 2,0 & 3,5 & 4 \\
\hline $\mathrm{X} 11$ & 5,0 & 7,0 & 4,0 & 7,0 & 5,5 & 2,0 & 3,5 & 8,5 & 8,5 & 8,5 & 6,5 & 6 \\
\hline
\end{tabular}

The reliability of the study is estimated with the help of ranks.:

$$
W=\frac{12 \sum_{i=1}^{m}\left(S_{i}-\bar{S}\right)^{2}}{n^{2}\left(m^{3}-m\right)}
$$

where $\mathrm{Si}$ - sum of ranks for object $\mathrm{i}$;

$$
\bar{S} \text { - average rank. }
$$

For the total ranks $\bar{S}=131$. According to formula (6), W=0,57. This value of the general consistency coefficient indicates a sufficient level of consistency and, therefore, sufficient accuracy of the findings of the expert survey. The final results of ranking the indicators of the construction organization technical facilities are shown in figure 1. 


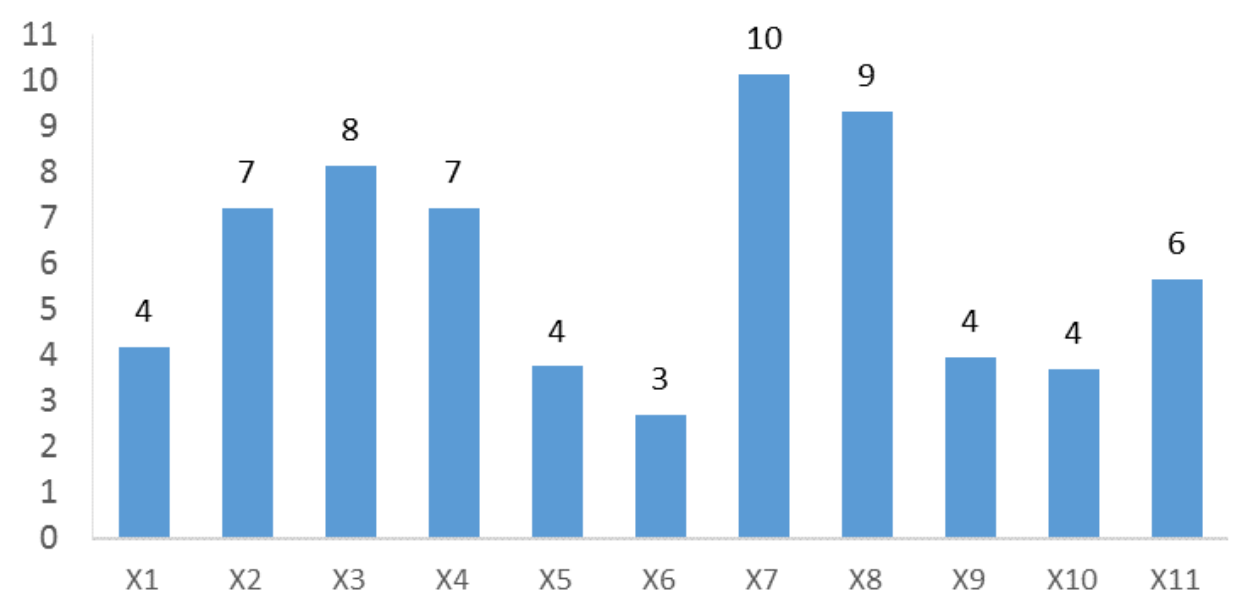

Fig. 1. Ranking the indicators of the construction organization technical facilities

The value obtained is divided by the number of indicators studied and multiplied by the average score of each indicator: To obtain the quantitative values of the weight coefficients from equation (1), we determine the sum of all the average estimates (graph 23, table 2) $\sum_{j=1}^{m} \overline{\mathrm{C}_{\boldsymbol{\imath}}}=88,8$. The reported value is divided by the number of indicators studied and multiplied by the average score of each indicator:

$$
d_{i}=\frac{1}{n} \sum_{j=1}^{m} \overline{\mathrm{C}_{\imath \jmath}} \cdot \overline{\mathrm{C}_{\imath \jmath}}
$$

As a result of calculating the weight coefficients of the technical facilities indicators according to equation (7), the general formulation of problem (1) is as follows::

$$
\begin{array}{r}
\mathrm{y}_{\mathrm{tp}}=0,103 \cdot X_{1}+0,086 \cdot X_{2}+0,077 \cdot X_{3}+0,086 \cdot X_{4}+0,105 \cdot X_{5}+ \\
+0,110 \cdot X_{6}+0,061 \cdot X_{7}+0,069 \cdot X_{8}+0,105 \cdot X_{9}+0,104 \cdot X_{10}+0,094 \cdot X_{11}
\end{array}
$$

where $X_{i}$ - discreet value of $i$ - factor.

\section{Discussion and conclusion}

Equation analysis (8) enables to identify the most significant indicators of technical facilities, such as (in descending order): coefficient of intensity of the construction equipment use, basic machines availability coefficient, coefficient of operators sufficiency, coefficient of operators qualification, ratio of the availability of machinists, coefficient of classroom machinists, level of equipment of basic machines, level of basic machines facilities.

\section{Recommendations}

Considering that high-rise construction faces a rather large number of tasks, the problem of the technical facilities of domestic construction companies requires a compulsory solution. Compliance with the level of equipment for the construction of high-rise buildings, which are classified as unique, can encourage domestic companies to participate in the construction of similar structures.

Today, high-rise construction in Russia is going through rough times; nevertheless, interest in high-rise construction continues to grow. 


\section{References}

1. L.A. Koklugina, A.V Koklugin. Technology and organization of construction of highrise multifunctional buildings: Textbook. (Kazan: Publishing house of Kazan state architectural university, 2016)

2. L. K. Petrenko, S.E. Mangilevskaya Scientific review, 7, 2014;

3. URL: https://regrazvitie.ru/perspektivy-stroitelstva-i-ekspluatatsii-neboskrebov-v-21veke;

4. URL: https://www.natural-sciences.ru/ru/article/view? id=30334;

5. URL: http://www.vseon.com/i/themes/sovremennaya-strojka/item/samye-vysokiezdaniya-rossii-2.html

6. Rules and regulations 267.1325800.2016 «Buildings and high-rise complexes. Rules of design"

7. V.V. Asaul. Economics of Construction. 1, 14-25 (2005)

8. A.N Asaul, M.K Starovoitov, R.A Faltinskiy. Cost management in construction (S.Petersburg: IPEV, 2009)

9. D.G. Babaeva Analysis of the state of fixed productive assets in industry // Bulletin of DGINH: collection of scientific works. Issue. X. Makhachkala, 2006. p. 76-81.

10. S.M. Buttaeva. Bulletin of the Russian state social university, 2(54). p.119-130 (2007)

11. D.P. Volkov, S.N. Nikolaev. Reliability of construction machinery and equipment. (Moscow, Vyshaya shkola,1979)

12. D.A. Dvizov, N.V. Skidanov, X Interuniversity scientific conference of young scientists and students of Volzhskiy, p.4-5 (2004)

13. V.N. Ivanov, R.F. Salikhov. Omsk scientific bulletin. Omsk: OmGTU, 1.92 - 94 (2007)

14. M.I. Kamenetskiy, M.F. Kostetskiy. Economics of construction, 4, 17-22 (2010)

15. E.P. Pankratov, O.E. Pankratova. Economics of construction. 3(33), 4-17 (2015)

16. S.V. Repin, A.V.Savelyev. Construction technique 31-35 (2006)

17. Z. R. Tuskaeva. International Journal of Applied Engineering Research, 6, 4369-4376 (2016)

18. Z.R. Tuskaeva. Software Procedia Engineering, 165, 1184-1191 (2016)

19. S.S.Uvarova, S.V. Belyaeva, V.S. Kankhva. Economic sustainability of construction companies and projects. (Scientific library of MSEU, Moscow, 2011)

20. E.S. Ventzel. Theory of probability: Textbook. $6^{\text {th }}$ edition. ( Vyshaya shkola, Moscow, 1999) 